Palimpsesto Vol. 11, № 18 (enero-junio, 2021): 73-90

Universidad de Santiago de Chile, ISSN 0718-5898

\author{
María Esther Castillo García \\ Conacyt \\ marescas2014@gmail.com
}

\title{
Acerca de lo sentido y de las conjeturas en Éste era un gato de Luis Arturo Ramos
}

\section{Meaning and Conjectures in Éste era un gato by Luis Arturo Ramos}

\begin{abstract}
Resumen
De lo que se siente, surge y comunica la poética de Luis Arturo Ramos (1947-), son aspectos semióticos poco estudiados por la crítica. Si bien cada ensayo o nota crítica acerca de Éste era un gato reflexiona sobre el argumento, la trama o el tema, pasa por alto el aspecto conjetural de su estructura. Estos supuestos me han dado el pretexto, o el subterfugio, de aventurarme en dos tópicos principales: el aspecto estético del discurso y el carácter conjetural de una estructura impuesta por una frase reiterativa de inicio a fin, "Quieres que te lo cuente otra vez", y que funge como el leitmotiv del clásico cuento de nunca acabar.
\end{abstract}

Palabras claves: Ramos, estética, conjetura, poética.

\begin{abstract}
What you can feel, what you can sense and communicate from Luis Arturo Ramos's (1947) poetics, are semiotic aspects understudied by the critics. Even when every essay or note of "This Was a Cat" define its every argument, story or plot, the conjectural aspect of its structure is overlooked. These pretenses have given me the excuse to venture within two main topics: the speech's aesthetic aspect and the conjectural character imposed by the reiterative phrase from start to finish, "Do you want me to tell you the story again?", and which serves as the leitmotiv of the classic endless tale.
\end{abstract}

Keywords: Ramos, aesthetic, conjecture, poetics. 
"Si supiera quién eres y quién soy / si supiese por qué eres y por qué soy /la vida perdería su intensidad lacerante/ Dejaría de ser lo que es en verdad/ el enigma sin fondo". Enigma, de José Emilio Pacheco

La obra de Luis Arturo Ramos (Minatitlán, Veracruz, Mx. 1947) ${ }^{1}$ ofrece a sus lectores un continuo gusto estético, una sabia virtud de contar historias y una conciencia profunda del ser humano y de nuestra realidad mexicana. Como bien recuerda el poeta Marco Antonio Campos (2005), sus filiaciones espirituales reconocen las obras de José Revueltas, Juan Rulfo, Sergio Galindo; William Faulkner, Julio Cortázar y Borges, yo agregaría los estilos de escritores españoles, desde el sarcasmo y el romanticismo de Quevedo, el esperpento de Valle-Inclán, hasta las voces de postguerra de Juan Marsé. Como el mismo Ramos ha reiterado en innumerables ocasiones, todo escritor debe ser antes que nada un buen lector y él lo es. Ha publicado ensayo, crónica, reseñas, cuentos, novelas y cuentos infantiles: Melomanías (1989), Siete veces el sueño (1974), Del tiempo y otros lugares (1979), Los viejos asesinos (1981), La señora de la fuente y otras parábolas de fin de siglo (1996), La voz de Coatl (1983), Violeta-Perú (1979), Intramuros (1983) Este era un gato (1988), La casa del ahorcado (1993), La señora de la fuente (1995), La mujer que quiso ser dios (2000), Los argentinos no existen (2005), Ricochet o los derechos de autor (2007), Mickey y sus amigos (2010), De puño y letra (2015) y Los motivos de Bayardo (2019).

Para indagar el sentido de la escritura de Ramos desde un punto de vista más semiótico que narratológico, o bajo cualquiera otra perspectiva que la crítica ha privilegiado acerca de la novela Éste era un gato, he decidido estudiarla como ese objeto estético que se transforma en experiencia. Desdoblar la experiencia de Éste era un gato en la refiguración lectora de este ensayo, significa explorar lo que se asuma como vivencia estética a través del discurso configurado por el autor en torno a la verdad del cuerpo sensible. La verdad se convierte en fragmentos de una historia personal que desea apoderarse o insertarse en la Historia nacional veracruzana.

Después de enlistar algunas opiniones críticas sobre el libro, expondré el argumento de la novela, posteriormente el sustento teórico, para corroborar esa experiencia estética literaria formulada por Ramos. La serie de eventos signados por la cotidianidad y por la surrealidad, engloba esa otra realidad fraguada por el narrador (alter ego del creador) que con parsimonia elabora un complot sólo advertido por el lector. La concurrencia de eventos entre el sujeto y el objeto perseguido subraya la importancia del cuerpo sentido, sintiente y padeciente. A partir de los cinco sentidos (o más), es como Luis Arturo Ramos logra hacernos mirar, sentir y comprender, cómo el mundo adquiere sentido para aquel que lo habita, lo sufre o lo disfruta.

\footnotetext{
${ }^{1}$ Ha sido profesor en la Universidad Veracruzana (UV), en la Universidad Nacional Autónoma de México (UNAM), en la Universidad de Missouri en Kansas City, es profesor emérito en la Universidad de Texas en El Paso y fue quien inauguró la Maestría en Creación Literaria Bilingüe. Existen numerosas tesis y artículos en diversas universidades de México y Estados Unidos. Ha dictado cursos sobre crónica, cuento chicano y formas y técnicas de ficción, en diversas Instituciones. Fue becario del Centro Mexicano de Escritores y ha sido galardonado con varios premios literarios: Premio Nacional de Narrativa, Premio Latinoamericano de Narrativa, Premio Nacional de Ensayo y finalista del Premio Mortiz-Planeta. Fue director de la revista La palabra y el hombre (UV) y de Revista de Literatura Mexicana (UTEP). Mantuvo diversos cargos editoriales y académicos.
} 


\section{Referentes críticos sobre la novela}

A continuación, enlisto algunos comentarios que parten de referentes teóricos y filosóficos sobre esta novela. López-Quiñones en "El fragmento y el vacío en Éste era un gato", realiza un estudio esquemático y minucioso de la secuencia de la trama; destaca el sentido unitario de los hechos y las elucubraciones de los personajes, especialmente la rareza de las voces fragmentarias que no fluyen de manera consecuente en el tiempo: "Los diferentes pasados y el presente de Alberto Bolaño funcionan como piezas incompatibles de un 'puzle' que nunca cuadra" (2005, p.270)2. Advierte López-Quiñones, de manera semejante a los demás críticos, que la relación autor-texto-recepción, es una constante del sustrato metaliterario que el autor destaca cada vez más. Puedo constatar este aspecto metalingüístico señalado por López-Quiñones en toda su narrativa. Para Enrique Serna, en "Las almas muertas de Luis Arturo", el entramado simbólico es lo más complejo y sugestivo, así revela el temor simbólico de Bolaño sobre los gatos que en él "ejerce un poder totémico sobre sus actos" (2005, p.42), habría que anotar, que las sentencias de Serna acerca de los personajes y ambientes de Ramos como 'enemigos de sí mismos' y la noción del paisaje veracruzano como una "ciudad onetiana" (2005, p.44), han corrido con fortuna en la mayor parte de la crítica; Serna, al contrario de Raymond Williams, que lo ubica en la postmodernidad, coincide con García Díaz al deslindarlo de cualquier cuadro clasificatorio. García Díaz, en "La mirada de los primeros años y los intersticios de la memoria", subraya la riqueza expresiva y la calidad estética que "trascienden influencias, generaciones, tendencias, grupos, exigencias editoriales o modas" (2005, p.189). Marco Antonio Campos, en "La historia es el enigma", resalta la trascendencia de los hitos historiográficos en la narrativa de Ramos, como uno de los nudos argumentativos en esta novela, es el caso de la invasión estadounidense de 1914. Campos agrega que "no hay escritor veracruzano que no tenga la obsesión temblorosa de los siete meses de la invasión en el puerto" (2005, p.87). Raymond Williams, en "La narrativa posmoderna de Luis Arturo Ramos...", y en diferentes artículos, ha reiterado la influencia de Julio Cortázar en el autor, así como su pertinencia generacional, sobre todo al enfocar el afán subversivo y autorreflexivo en toda la obra; también destaca los rasgos de "storytellers" de los personajes centrales: "hombres comunes, como Alberto Bolaño o Roger Copeland, de poca o ninguna pretensión literaria” (2005:152). García Núñez, en "Éste era un gato: ingeniosa vuelta al catecismo", refrenda los temas en donde subyace "la lucha secular entre Dios y el Diablo", manifestada alegóricamente en el enfrentamiento del Arcángel San Miguel y el Dragón, en las estampas que intrigan al mismo Alberto Bolaño, a su amigo Miguel Ángel Herrador y al abuelo Sebastián Herrador, un colaboracionista en la invasión norteamericana y asesinado posteriormente en la Guerra Cristera (2005). Elvira Villamil, en "Espacio discursivo autoconsciente", destaca en la síntesis de su tesis de grado, las relaciones metaliterarias basadas en la teoría de la recepción y efecto estético (2005) Aguilera Garramuño, en "Luis Arturo Ramos: del pesimismo a la ironía", relaciona, inopinadamente, pienso, algunos aspectos burocráticos del autor persona, que, según él, influyen en el tono irónico y tortuoso; tonos que ya Alberto Paredes había señalado. Según Garramuño, las atmósferas opresivas, los personajes acompañados y

\footnotetext{
${ }^{2}$ Los diferentes comentarios aquí enlistados, excepto el de Vázquez Rentería, forman parte de la antología intitulada: Acercamientos a la narrativa de Luis Arturo Ramos, compilada por Camps y Moreno, con el prólogo del poeta Marco Antonio Campos (2005). Todos han sido difundidos de manera previa en diferentes revistas. Cabe destacar que, hasta la fecha, no se han publicado nuevas aproximaciones a esta novela. De aquí el pretendido alcance de esta participación que desea invitar a los lectores de otras latitudes a adentrarse en la obra de Ramos.
} 
perseguidos por la ausencia, la desgracia y la violencia, coinciden con el tenor político que el autor enfrentaba en sus funciones laborales. Por su parte, el investigador, José Homero destaca el tono fársico o paródico y el derrotero escatológico, en "La jiga de la muerte de Luis Arturo Ramos". Vásquez Rentería, en "De la escritura a la inmersión en la opacidad pegajosa de la condición humana: Éste era un gato" (2012), resalta la importancia del lenguaje retórico/simbólico de la novela, la decisión de qué elementos elogiar en la escritura, centra el efecto receptivo que las palabras producen, la prosopopeya que humaniza, el símil que moldea al personaje y permite indagar en la psique de aquel.

\section{La propuesta argumental de Éste era un gato}

La novela está narrada en tercera persona desde la perspectiva del personaje Alberto Bolaño, un joven obsesionado por la aparición y el posterior asesinato del viejo francotirador Mr. Copeland. Un ex marine que participara en el asalto al puerto de Veracruz (México), durante la invasión perpetrada por los estadounidenses en $1914^{3}$ (del 21 de abril al 23 de noviembre), y que, sesenta años después, desembarcara en el mismo lugar que creía perdido en la memoria.

El matiz neurótico del narrador Bolaño justifica el desarrollo intermitente de una trama que no permite la secuencia narrativa de causa y efecto. El orden que el narrador establece tiene que ver tanto con los juicios y conspiraciones del uno contra el Otro, como con las interminables elucubraciones sobre sí mismo, sus sueños premonitorios y justicieros, sus temores y pulsiones, es decir, "aquella zona de la vida interior del sujeto no sometida a una lógica de la acción pragmática sino guiada por los principios de la pasión" (Filinich, 2003, p.86). Entre evidencias y conjuras se mezcla un ideario de origen fascista que confronta las posturas éticas de los personajes involucrados. Con la amalgama de emociones y fantasías, Bolaño pretende justificar su afán persecutorio tras la sombra de un francotirador que surge para beneficio de su intriga y de la interpretación de la novela. Los relatos históricos y las reflexiones asumidas revelan no pocas incongruencias. La no linealidad de la trama le permite a Ramos, ir y venir, imaginar y transcribir una serie de hipótesis, que convienen más a la mente de Bolaño, que al tiempo de la memoria histórica sobre esa invasión al Puerto en 1914. Un coro de voces legendarias invoca el hecho, en confrontación con el imaginario de unos jóvenes actores que cronológicamente no lo padecieron. Lo sorprendente es que ellos desarrollaran una intrincada nostalgia acerca del evento. La polifonía incluye las opiniones de parientes y amigos, el rumor de otros actores, incluso los pensamientos de Mr. Copeland, además de la voz de Miguel Ángel Herrador, el otro adolescente que depende y soporta el complot del astuto narrador. La serie de conjeturas elaboradas por Alberto Bolaño sustenta la estructura de esta novela que recuerda su semejanza con otras narrativas, pienso específicamente en Morirás lejos de José Emilio Pacheco, cuando el que mira y es mirado mantienen la expectación lectora hasta el final. La intriga, por ende, se sostiene en la relación triangular entre Alberto Bolaño, su amigo Miguel Ángel Herrador, y el viejo soldado norteamericano, Roger Copeland.

\footnotetext{
${ }^{3}$ Veracruz fue puerto de entrada para los españoles en 1519 y una de las vías definitivas para las invasiones estadounidenses como la de los años 1846-1848, cuando después de derrotar al ejército mexicano y con base en los tratados de Guadalupe-Hidalgo, acabarían apropiándose de la mitad del territorio. La de 1914, no tuvo pretexto real. Los marines acabarían yéndose después de arrasar partes de la ciudad y de ejecutar a numerosos civiles.
} 
La descripción de la figura del soldado apostado en el borde de la ventana de un viejo hotel abre el interés del texto: ¿Qué mira a través de ella? Quizás nada, quizás la realidad histórica que desea contar Bolaño, quizás esa otra realidad íntima de un viejo ex combatiente. Mr. Copeland, arriba a Veracruz en dos ocasiones incomparables, la primera en el buque de guerra Praire, como combatiente en la invasión que Estados Unidos infringiera a nuestro país durante la ocupación del puerto veracruzano en el año de 1914, y, la segunda, sesenta años después, como excursionista a bordo del Sunflower, un barco turístico. Desembarca con dos pretextos, uno es evidente, para aniquilar a terceros, y el otro ni él lo sabe, el de su propia muerte. Cuando viaja como turista (según el narrador) le asaltan todos los recuerdos, pero sólo uno es importante y proviene de la figura evocada de Teresa Triana o Tirana [el equívoco eufónico de su nombre], la "única mujer" que él presume haber amado durante los meses de ocupación. Como descubriremos más tarde, el gato encerrado ideado por los jóvenes es que él debía regresar para pagar con su vida la culpa imputable a la invasión extranjera. Tirana es el cuerpo, la figura que resurge en el primer plano de las motivaciones del americano que regresa, después, esta figura pasará al trasfondo para que emerja el motivo de los jóvenes, el de una expiación histórica y ética, aunque el narrador Bolaño advierta: "Nadie, ni siquiera yo, supo a ciencia cierta la causa de su regreso" (22).

Así pues, Ramos acompaña la emergencia de Triana en la memoria de Mr. Copeland con las figuras de los dos adolescentes, Miguel Ángel Herrador (apodado familiarmente Minino) y Alberto Bolaño; estas figuras le permiten al autor persona transcribir una serie de pasiones y de historias, de conjeturas sin fin, que poseen el talante de los cambios de perspectiva propios de la juventud, de la pasión y el resentimiento, entre muchas fantasías y pocas certezas. Ambos adolescentes se presentan en la trama como un par de periodistas en ciernes. Este trabajo es el subterfugio que avala los encuentros, conversaciones y entrevistas futuros con Mr. Copeland, para, precisamente, configurar el registro verosímil de la escritura de esta historia. El autor implicado describe los necesarios ritos de iniciación -de la niñez a la madurez- física y mental, para conducir el enfrentamiento emocional que irrumpe ante el descubrimiento de un soldado que estuvo combatiendo en la realidad historiográfica relatada por sus abuelos. La aventura deseada presenta una serie de ritos que subrayan el comienzo y el tránsito de las experiencias juveniles, ideológicas y pasionales; primero en el imaginario, como debe ser, después en las relaciones fraternas y, sobre todo, en el despertar del sexo. Las situaciones típicas alrededor de las batallas y camorras juveniles, del sexo y aún el abuso sexual por ellos cometido, fabulan el umbral que suscita la intriga del homicidio del excombatiente. El asesinato de Mr. Copeland sucede 17 meses después de su arribo, el hecho ubica la validez de una conjetura de tipo policial en el imaginario del joven periodista Bolaño: ¿Quién mató a Mr. Copeland?

A conveniencia del relato se configuran algunos episodios inherentes a las novelas de aprendizaje (o bildungsroman), pero lo más ostensible es lo que está signado por los tópicos del homicidio y la traición. La desazón, la venganza, y el hecho de la muerte, configuran esta isotopía recurrente que une anímicamente las reacciones físicas de los jóvenes. El homicidio de Mr. Copeland, si realmente ocurre, ocupa sólo un instante, pero se glosa y describe desde distintos enfoques basados en la conjetura, que debe reiterar el leitmotiv: "Quieres que te lo cuente otra vez?". La necesidad de volver a relatar el acto de muerte conlleva venganza, justicia, temor, y todos los agravantes personales, fantásticos e históricos, que además están representados a través de una repetida ecfrasis [o lectura iconotextual], en la imagen vengadora de una copia pictórica que muestra el cuerpo acorazado de San Miguel Arcángel venciendo al demonio, y que, no por nada, el joven Miguel Ángel mantiene en la pared de su recámara. La descripción de este 
icono, que, según Bolaño, arrebata el imaginario de Miguel Ángel, se alude incansablemente como la alegoría que siembra en la mente de los adolescentes la semilla de una venganza, así sea anacrónica; vencer el mal, al demonio y a todas las ignominias padecidas en el imaginario y en la realidad histórica, es justificación suficiente para acabar con ese excombatiente Mr. Copeland que, casualmente, como en las novelas policíacas, ha regresado al lugar del crimen. El temor y la angustia subyace en los posibles efectos de una revancha personal disfrazada de histórica, que forman parte del alarde adolescente de Miguel Ángel: "Que no existe sitio alguno que no podamos llegar. Que, del otro lado de la esquina, al final de la escalera, detrás de todas las puertas, se agazapa el miedo. Si nosotros somos el peligro entonces no tenemos nada que temer" $(205)^{4}$

Entre estos jóvenes (Alberto y Miguel Ángel) se entabla una amistad y una rivalidad que sólo de manera paulatina expresa su cambio; al principio pareciera que Miguel Ángel domina a Bolaño, pero en realidad es lo contrario, Alberto es quien narra y mueve los hilos de la trama, la traición o el complot. A diferencia de Miguel Ángel, Bolaño no posee la genealogía de prosapia provinciana ni de atrocidades legendarias y familiares que justifican la vida y las emociones de Miguel Ángel. Alberto no se exalta, piensa y planea, y, por ello, puede ser el artífice de la conjura.

De Alberto sabemos que mantiene tal vínculo con la madre, que transforma su vida en el espacio inmanente que determina la experiencia de las futuras relaciones con el Otro; la madre propicia en el hijo un estadio de irrealidad, de interpretación mística que se transforman en expiaciones oníricas. La madre sueña, imagina y conserva el recuerdo del marido muerto, con la resignación de "oficiante de una religión privada en la que sus recuerdos fueron catedrales y sus sueños revelaciones sin las que ninguna doctrina es capaz de existir" $(46)^{5}$. El sexo temprano lo había ensayado con Macrina ${ }^{6}$, la sirvienta de la familia, la joven mujer, que no por casualidad resulta violentada sexualmente por toda la pandilla de Los animales. La nota sobre un hermano mayor y su muerte temprana se convierte en una imagen dolorosa, pero poco perceptible, a diferencia de la figura del padre muerto, que hereda en Bolaño el interés por otra mitología fundada en la Historia ${ }^{7}$, evidente en el apreciable sustrato historiográfico que enlaza al narrador y al autor persona. ${ }^{8}$

Miguel Ángel Herrador, apodado Minino, presenta esas facetas intercambiables que Bolaño pervierte para ajustar el nombre al sentido del icono de San Miguel Arcángel, y para

\footnotetext{
${ }^{4}$ Pensamientos y acciones de estos jóvenes traerán a la mente lectora diferentes novelas de aprendizaje, por ejemplo, el poder que poseía Max Demian sobre Emil Sinclair en Demian, de Hesse. Si la confrontamos con Éste era un gato, Ramos presenta un Sinclair (Alberto Bolaño) que se transforma en el verdadero Demian.

${ }^{5}$ Nota al calce es advertirle al lector de este ensayo, que esta premisa basada en la relación madre e hijo es el sustento argumental de la excelente última novela de la trilogía: La mujer que quiso ser dios (2000).

${ }^{6}$ Macrina, en ocasiones, también recibe el adjetivo de gata. El adjetivo soez e injurioso, ha sido utilizado en la jerga lingüística mexicana, para referirse a las trabajadoras domésticas,

${ }^{7} \mathrm{H} /$ historia: requerimos hacer la diferencia entre la Historia con mayúscula como disciplina y la historia como sinónimo de relato.

${ }^{8}$ El remanente historiográfico que proviene de las charlas entre el autor persona y su propio padre es algo sabido y reconocido en entrevistas y en charlas con amigos. El repertorio acerca de las batallas históricas que sucedieron en nuestro país y en la historiografía de la Guerra Civil Española se manifiesta en la trilogía (Intramuros, Éste era un gato, La mujer que quiso ser dios), e incluso se aluden en las más recientes, De puño y letra y Los motivos de Bayardo, novelas en donde el remanente histórico se menciona, a pesar de no ser trascendental para la creación de la fábula. Hay una nostalgia muy acentuada en Ramos relacionada con esas batallas. De este tema me ocupo en otro ensayo a propósito de Intramuros.
} 
reconvertir la noción de un doméstico "minino" en tigre. El árbol genealógico de Miguel se ata al destino de los Herrador con todo lujo de detalles. Comienza desde la mención de un primer Ernesto, el bisabuelo médico; Sebastián, el abuelo cristero fusilado; el segundo Ernesto, padre de Miguel Ángel, dedicado a la escritura de crónicas y editoriales, heredero del periódico veracruzano La Opinión. Miguel Ángel, según la voz narrativa, creía con fruición que se había saltado una generación, porque más que al padre, deseaba parecerse al controvertido abuelo Sebastián, con todas las connotaciones del martirologio impresas en el nombre. La evocación del abuelo cristero reúne una amalgama de misticismo y combate, remordimientos e indecisiones que lo perturbaron toda su vida; el nieto identifica para sí el repertorio del abuelo como un legado venturoso y activo, mucho más interesante que la escritura de notas periodísticas de su padre. Desde su mirada, el padre carecía de la enjundia del hombre de acción que representaba el abuelo, ese personaje que no sólo se empeñaba en sufrir, sino en mostrar la originalidad de su sufrimiento.

La atracción que ejerce Miguel Ángel en Alberto debe su trascendencia a esa leyenda familiar sobre la lucha cristera. Quizás Alberto, ante tal carencia de aventuras heredadas, aprovecha la oportunidad de mostrar su superioridad infundiendo entre el hijo y en el padre la mutua sospecha de haber dado muerte a Mr. Copeland. Las reflexiones que el mismo Miguel Ángel establece como consignas y sentencias, Alberto las empata con respuestas, pensamientos y rectificaciones, que denotan también el nivel metanarrativo de la novela. Miguel Ángel es quien introduce a Bolaño en la ya formada pandilla, apodada Los animales (Águila, Cuervo, Delfín y el nominado Baca), Alberto se incorpora a ella con el mismo entusiasmo iniciático que después descubriría en el burdel de doña Teresa Triana (la postrera Tirana), cuando surge su "enamoramiento por las putas". Teresa Triana, de manera asombrosa, es la misma persona, la misma figura femenina, que vale en tanto objeto, pretexto del deseo, amor, odio, resentimiento, culpa y expiación, que, según la trama, Mr. Copeland debe cumplir, regresando al puerto veracruzano, al mismo hotel, al mismo cuarto número 509, y a situarse en la misma ventana, que otrora le sirviera de punto de mira para jugar al tiro al blanco y matar a los enemigos mexicanos.

Roger Copeland es el eje cardinal que justifica no sólo el miedo y la revancha que los jóvenes no podían saciar en su insípido deambular portuario; Mr. Copeland era la cara del enemigo jurado que Miguel Ángel requería para equiparar su vida a la memoria legendaria del abuelo. Sin la figura de un soldado no existiría el móvil, la intriga necesaria en la vida de los actores ni en la novela, sin él no existiría el qué, cómo y cuándo, de todas y cada una de las acciones sustentadas por la trama. El narrador expone esta necesidad primaria de forma metalingüística en el resaltado entre paréntesis:

Miguel Angel ${ }^{9}$ no encontraba todavía ni nombre ni cara para su enemigo [...] Era el miedo lo que convertía a los demás en enemigo. Escondí mi culpa y mi traición con la vergüenza de quien oculta la ropa interior agujereada. Llevé mi temor pegado al cuerpo consciente de su presencia y de la necesidad de mantenerlo oculto. (Tal era la situación cuando apareció Mr. Copeland. Entonces vislumbre la oportunidad de otorgar sentido a los acontecimientos con el uso de esa pieza que inopinadamente aparecía en mis manos. Mejor aún, advertí el momento de acomodar las fichas al servicio de mi conveniencia. Al menos eso creí por aquellos meses). (205)

\footnotetext{
${ }^{9}$ Conviene aclarar que el sustantivo Ángel, aparece sin acento gráfico en el libro.
} 
La historia de Mr. Copeland, "soldado raso, marinero fracasado", "tirador de primera", "capitán retirado", además de su inserción para fraguar el conflicto del temor, la muerte y la revancha, muestra también el panorama personal e historiográfico que lo llevara a comparecer en la invasión norteamericana ese 21 de abril de 1914. El plano íntimo que rige la presencia femenina de Tirana, "la mujer de ojo de humo", consigna dos encuentros entre ella y el soldado. Copeland, en aquel asalto, había eliminado al hermano de Teresa Triana durante la invasión, en consecuencia, ella, en venganza, trata de asesinarlo, pero sólo consigue dispararle un tiro a la pierna. El balazo le provocará una singular cicatriz, cuya marca surca el recuerdo ominoso que une penosamente a la pareja, y que funda gran parte de la estesia discursiva [como veremos más adelante] en el relato. El segundo inverosímil encuentro focaliza la mirada invertida del antiguo francotirador, "Tirana lo miró, quedó sólo el odio que había levantado la pistola 60 años atrás [...] se percató de que Tirana apartaba la vista de sus ojos y la clavaba ahí donde su mano iba y venía en un acto involuntario de protección y recordatorio" (208).

El narrador relata y describe fragmentos de la vida civil y militar de Mr. Copeland, atados a la esfera invocadora de la madre, ella fue quien describió para Copeland las huellas fosilizadas del mar en las llanuras de su Oklahoma. Una memoria prehistórica que dentellaba el paso del mar, que sólo se reconvierte en vivencia cuando el marine atravesara el océano rumbo a Veracruz con la tropa invasora. Hay que aclarar, porque no hay testimonio sin Historia, que esa invasión al puerto ajusta el interés de Ramos por la Historia en general, pero sobre todo por las invasiones e inmigraciones veracruzanas.

En las páginas finales de la novela, Alberto sugiere su propia imagen homicida, sentado en el butacón del cuarto 509, en donde Mr. Copeland esperase la muerte redentora. Alberto espera pacientemente el retorno del viaje de estudios de Miguel Ángel en España, éste le había enviado por carta una advertencia: "Cuando te vea sabré..., escribió [...]. Y mi cara, lo he constatado en el espejo, está empapada por la traición y el remordimiento." La enunciación final repite con terquedad la interpelación y la conjetura que asedia el relato de Bolaño: "Quieres que te lo cuente otra vez". ¿Quién asesinó a Roger Copeland?

\section{La semiótica de lo sentido y el sentido}

"Es por la mediación del cuerpo percibiente que el mundo se transforma en sentido" (Greimas y Fontanille, 1995, p.13). Esta afirmación enlaza las premisas ideológicas del narrador Bolaño que asegura: "Llevé mi temor pegado al cuerpo consciente de su presencia y de la necesidad de mantenerlo oculto". Este tipo de enunciados son trascendentes para describir lo inteligible del discurso poético en la información que nos proporcionan los cinco sentidos a lo largo de esta novela, una de las obras más sensibles del autor, en tanto trato de valorar la episteme poética [la forma de conocimiento que proporciona lo literario a través del discurso] que surge entre aquellas narrativas y ésta. Este era un gato narra con particular fuerza la cotidianeidad y lo accidental de la vida, lo ilusorio del deseo y la melancolía, la credibilidad mistificada contra la plausibilidad de los datos historiográficos. Como hemos referido, es como si lo mirado y dicho, fuese equivalente a lo imaginado en la mente de los jóvenes personajes. Cada suceso vivido o imaginado es captado para revelar que la percepción narrada por Bolaño hacia los demás (Miguel Ángel, Mr. Copeland, Triana) ha sido premeditada. Como si en cada acto su percepción fuese lo fundamental del relato y de la trama. Como si lo que Bolaño nos ofrece 
tuviese ese otro sentido que escapa de lo unívoco que rodea el pensar y el actuar de los sujetos receptores de su relato. En realidad, las voces y la focalización, al provenir del sujeto que mira y describe han sido interpretadas para acoplarse al mundo que sólo él valora. Este mundo, en consecuencia, implica la duplicidad de lo narrado. Uno en donde la voz narrativa trata de reconocerse a sí mismo en el Otro y así fraguar la traición. El lector debe adivinar las causas de ese complot, de ese beso de Judas, perpetrado por Bolaño en contra de Miguel Ángel.

Los personajes de Ramos, aquí y en otras novelas, aparentan que nada depende de su voluntad sino de lo súbito que aparece y sucede, y que, por ende, son signos que deben saber interpretarse para poder pronunciarse. Como si todo fuese un mero accidente que cambia la mirada sobre el mundo externo, "un determinado componente sensible del ambiente, en vez de mantenerse indiferente, distanciado y casi imperceptible, ahora 'entra', por decirlo así, en él, lo 'absorbe' lo domina, le impone su presencia..." (Landowski,1999, p.13). Los cambios de perspectiva de Bolaño, la aparente decisión de Mr. Copeland de quedarse en el mismo lugar en espera de lo fortuito, la increíble reaparición de Triana, suceden por cuestiones aleatorias; las acciones y los pensamientos de los personajes se alteran a partir de una conmoción física tras el encuentro de todos contra todos.

Pensemos asimismo que, literariamente, cada novela es también una aventura, que, aunque lingüística [porque el lenguaje la articula y de palabras hablamos], se aprehende como si fuese corpórea, porque nos provoca, porque no permanece inocua en la vida de los actores ni en la aprehensión lectora. Al contrario, como un movimiento de sístole y diástole, la palabra atenúa o agrava lo descrito como acontecimiento, y, por ende, se requiere de constantes aventuras que en el instante se configuran y luego se desplazan. Recordemos que el artificio poético (y por ende discursivo), para captarse, requiere del juego o movimiento a través de tropos; la sustitución, la progresión y la condensación de elementos fonéticos, morfológicos, semánticos, funcionan con su plasticidad para poder ser materia visible. Cada aventura, lingüísticamente aceptada como "real" es requerida para seguir encadenando escenas y escenarios. Mismos que colmarán tanto el presente histórico de la novela, como la nostalgia de lo prometido o aún de lo ausente en esa futura presencia que descubre el desenlace en la expectativa de todos los personajes (Bolaño, Miguel Ángel, Triana), y en la expectativa lectora.

Es en el Yo del lector en quien se replica la satisfacción (o insatisfacción) de la revelación captada como descubrimiento, a sabiendas de que hay indicios e informaciones, y que debe existir en tanto proceso; cuando el lector espera lo segundo y lo subsecuente de un engranaje entre la negación de lo que se desea y lo que se obtiene. Este juego de expectativas, no obstante, ni forzosa ni únicamente, corroboran su proveniencia del objeto hacia el sujeto, porque la propia ficción del sujeto Bolaño puede constituirse como su propio objeto. La aventura, así sean palabras y discursos, semejan la realidad de un sentimiento y de un pensamiento encapsulados en la voluntad del narrador cuyo imperativo transforma lo inteligible en su verdad. Así se comprende que, entre la denotación y la connotación del discurso poético vehiculado por los actores, se guarden estas eventualidades o accidentes que no lo son, porque están construidos por el narrador que, evidentemente, oculta al demiurgo.

Entonces hay una intencionalidad y por ende una progresividad, que relaciona las imágenes que sólo parecen incidentales. La habilidad poética de Ramos propicia este hacer estético con carácter metódico, aunque parezca azaroso. El azar forma parte de la historia humana, pero no de las estrategias compositivas con las cuales el autor procura hacer comprender al lector la estructura poética de su objeto, esto es, de lo que se trata su libro. 
Ramos no puede mantenerse en la construcción de un sólo objeto de valor (cosa, situación, persona), necesita del relato, de la $\mathrm{H} /$ historia aquella sabida y relatada a través de la escucha y de los libros que relatan la etapa intervencionista en nuestro país, y, sobre todo, en $s u$ Veracruz. Hay que crear contexto para que todo vuelva a suceder. Eso que se constituye como el evento en la vida de los personajes Alberto Bolaño y Miguel Ángel sólo puede suceder si aparece material y objetual en la presencia, más milagrosa que casual, del personaje Mr. Copeland. Él debería ser ajeno a la historia de vida de los jóvenes, pero el narrador lo precisa para hacerla propia, para que la $\mathrm{H} / \mathrm{historia}$ se repita (Quieres que te lo cuente otra vez). Porque fue el tiempo y la vida del excombatiente estadounidense, pero sólo con la preeminencia de su emergencia real o figurativo, el demiurgo puede hacerlo formar parte de un triángulo indisoluble. La relación tríadica (Miguel Ángel, Bolaño y Mr. Copeland) parece una gracia providencial, así debe ser para conseguir la consecución de la trama; Mr. Copeland debe concurrir para que se repita la historia, por eso su figura inaugura el íncipit textual del libro. El encuentro de los adolescentes con esta aventura cobra sentido porque se cifra como el descubrimiento que ellos logran o que tiene lugar porque ellos la crean. Debe seguir dentro y fuera de su historia, e incluso dentro y fuera de la Historia. Recordemos que la Historia es histórica "sólo si se la mira, y para mirarla es necesario estar excluido de ella" (Barthes, 1989, p.105). En la imposibilidad cronológica de haber sido testigo de aquellos hechos pretéritos, Ramos debe establecer esta otra coyuntura que origina la intelección inclusiva de la conjetura y del acto de poder escribirla o reinventarla en su propio tiempo presente. El vórtice del triángulo configurado entre los jóvenes y el ex combatiente se transforma en la hazaña, en el riesgo mortal que ofrece sentido a la novela, porque el temor y el hecho fraguado en el crimen, significa encontrarse preso e indeciso en la bifurcación de esas vidas paralelas que el demiurgo decide cruzar. La coyuntura suscita la continuidad del relato en la trama, porque la historia debe adoptarse, adaptarse y seguir, aún fuera de sí misma, en la mente de sus receptores. Es el autor quien debe prevenir caer en la anestesia después de la contundencia de cada escena. El lector, para continuar, debe obtener y aspirar a más revelaciones, suspender su propia credibilidad para creer hoy, como siempre, en las máscaras antiheroicas que persistentemente nos presenta la narrativa de Ramos.

Adivino, a la sazón, la sonrisa irónica del autor en este hacer creer complejo que él manipula, a través de un relato con personajes que se muestran sintientes y pensantes, presentes en su propia historia, porque aparentan vivir experiencias enunciadas y descritas como si fuesen sensibles y cognoscentes, y cuya función en la trama, siguiendo a Landowski, "sería substituir lo sentido por el sentido, la sensación por la intelección" (1999, p.21).

Landowski pregunta si la experiencia supone la captación de su emergencia sólo como presencia, o si acaso, porque nuestra relación con el arte pone en cuestión un modo específico de aprehensión del sí mismo por mediación del otro: "por la mediación de esa forma particular de alteridad que es precisamente una 'obra', esa cosa que, situada frente a nosotros, más que ser el objeto de nuestra lectura, nos constituye" (1999, p.273). Proclamar la experiencia estética implica aprehenderla, admitir que se trasciende la estesia [la pura capacidad de sentir] al arribo de la corporeidad. Que a través del cuerpo se toma parte de lo inteligible de eso sensible que aprehendemos. Experiencia, porque lo que aparece ante la mirada del sujeto reaparece refigurado un tanto objetivamente en él o en los cuerpos. Como deseamos hacer notar en esta novela, Ramos precisa describir y enunciar los cuerpos y su sentir (sexo, aversión, agonía, etc.) como esas imágenes posibles que refiguran el imaginario de los tres personajes centrales. Los cuerpos de cada uno de ellos aparecen en un espacio y tiempos determinados, en tanto sus relaciones interpersonales como en sus relaciones contextuales o $\mathrm{H} /$ históricas. Este efecto de presencia, para 
convertirse en experiencia debe crearlo Ramos sobre el plano de las figuras, de los personajes, para que se signifique. Los personajes están presentes no sólo porque el narrador lo dice, sino porque describe la complexión física del cuerpo, del gesto, la manera de moverse, la postura. "Su modo de ser parece volver a decir a propósito de algo diferente de ella misma" (Landowski, p.276).

Reitero el efecto de presencia en la figuratividad del cuerpo de Copeland ante la mirada y la presencia de Tirana:

Tirana permaneció en el umbral como si temiera que su paso provocara el derrumbe del edificio. Se miraron protegidos por la distancia, como aquella primera vez. Mr. Copeland le ofreció el cuerpo habitado por la desnudez entera y ella lo rechazó con un gesto irónico. En la forma que un viejo observa a otro persiste la envidia o el insano regocijo de quien cree haber soportado con mejor fortuna el paso del tiempo, pero cuando Tirana lo miró, quedó sólo el odio, porque la piedad, el cariño y la memoria, se fueron desprendiendo de la mirada como gotas que escurren por una veladora de cera [...] Y lo que resultó peor, descubrió que se trataba del mismo odio que había levantado la pistola 60 años atrás. Acuciado por el recuerdo, Mr. Copeland llevó su mano al muslo izquierdo y acarició la cicatriz. Siguió el diseño, el espinazo del costurón, el orificio. Se percató que Tirana apartaba la vista de sus ojos y la clavaba ahí, donde su mano iba y venía en un acto involuntario de protección y recordatorio. (208)

El desarrollo sintagmático, donde el elemento que reaparece constantemente es la mirada sobre el cuerpo, se hace eco a partir del gesto irónico advertido por el desdoblamiento narrativo, pero lo que trasciende es el gesto y el movimiento de la mano sobre la cicatriz del muslo. El dolor [se] identifica [en] la memoria, porque facilita retroactivamente su sentido a través del dolor fosilizado como cicatriz [como aquel mar fosilizado de su Oklahoma]. La pasión causada por ese específico odio cimbra el efecto de resonancia y contraste entre lo que siente el viejo y su desprendimiento en ella. Existe un orden enunciativo y descriptivo, una gestualidad en la mano que palpa la cicatriz en el muslo, a su vez, la textura de su relieve tiene el propósito de reenviar a Copeland a la pretérita imagen de él mismo, antes y después de que Tirana le disparase en venganza por el asesinato del hermano. Hay un tono de voz que empata la mirada irónica de ambos, confundiendo sinestésicamente el amor y el odio en una isotopía del sentimiento. Más allá de esas actitudes que el narrador describe, se percibe el tiempo y el espacio, hubo un antes, un lugar para el amor, y un después para este odio estancado en el presente. Hay figura evocada y una presencia invocada, presente y actual, donde el eco sinestésico permite la plasticidad de la imagen del encuentro/desencuentro. La gravitación de la escena puesta en discurso está formulada también por las condiciones de reconocimiento de la relación y el sentimiento de los personajes, que intercambian la mirada en la misma reiteración del narrador que autentifica los elementos descritos: "Imaginar el asedio que descubrí en el monólogo de Mr. Copeland no fue difícil. La memoria guarda gestos, entornos, tinturas con los que luego resulta sencillo vestir a las palabras" (208). Este reenvío metalingüístico de la imagen del pasado (memoria) al tiempo futuro y actual afina la perspectiva, modula el matiz de la copresencia que nos hacer ver y volver a ver como si fuese una retro-lectura, sobre el connato de relaciones pasadas y presentes entre los dos personajes. Simplemente en la duración de la escena, y después, en los párrafos discursivos del narrador, poco queda entre líneas; el signo se traduce y otorga sentido al descubrirse: "La memoria provee con un vasto catálogo de formas y dibujos, de esencias y temperaturas que luego 
uno se va encargando de colocar en el sitio que considere más aproximado. Si se falla o se acierta, si la historia que se oye resulta después deformada por la imaginación, importa poco" (208).

La cicatriz, emplazada en cada trecho descriptivo, subraya las reacciones gestuales de Copeland, la cicatriz recuerda una reconstitución de la epidermis, capas laceradas se expulsan para ceder su lugar a una nueva piel que en su textura marca la antigua herida. La cicatriz es, por sí misma, una marca de lo sentido y de lo vivido por el propio cuerpo, la experiencia vivida es sólo su impronta. Como supone Iván Ruiz en "Piel herida" (2006), es la piel, concebida desde los fundamentos semióticos, donde puede ponerse a prueba en la obra de arte.

El eje semántico refiere la calidad material del cuerpo en la colocación del ángulo de la mirada, es lo que le permite al narrador acentuar el registro del imaginario en esos dos personajes que se miran, del narrador que los mira y reivindica metalingüísticamente, y del lector que lo registra y acepta, en recompensa de su disponibilidad para admitir ese instante preciso como un acontecimiento.

Un acontecer artístico y casi físico soportado en la mirada y en el imaginario del lector que puede suspender su mirada y cognición, acogido por esta experiencia estética. Aquí otro ejemplo de esta experiencia en la imagen corporal que triangula la mirada:

Miguel Angel y yo miramos a Mr. Copeland mordisqueado por el espanto, atenazado por un sentimiento que no conoció 60 años atrás, cuando era cierto y no mera caricatura. Porque de pronto lo veíamos deformarse en una sola arruga y escupir por una boca consumida por los años, el miedo que le llegaba a destiempo. Señalaba el sitio [...] se quejaba de la pestilencia, los gritos de dolor, la visión del cadáver reventado por las dum dum, sonriendo con cada una de sus heridas, abierto al viento y a las palomas como un trapo desgarrado y viejo [...] Sumiso, atento a su propia descomposición, el cuerpo sudaba un vapor denso y mal oliente. [...] Se convirtió frente a sus ojos en un bulto deforme donde el sol y el viento resecaron la sangre hasta cubrirlo con una costra que lo alejaba de toda posibilidad humana. La cabeza desflorada resultaba lo único reconocible por la sencilla razón de que el cráneo siempre supone lo más humano de los huesos. Por la noche el resplandor de la luna lo cobijó con una paletada de arena. Lo embelleció al despojarlo de toda semejanza humana. Lo convirtió en duna, en médano tibio y frágil, temeroso de que el menor movimiento, el roce más involuntario, deformaran la perfección del promontorio. (234-235)

La visualidad hace posible la visibilidad del cuerpo que se enfoca como el cuadro de una y otra piel herida, será otra cicatriz la que se signifique como una marca de contacto con la experiencia vivida. La frontera entre la carne y su envoltura o entre lo que permanece como una herida a flor de piel, remarca el paso hiriente de las balas [el dum dum] y sólo quedará el cráneo que engendra el valor sensible de lo humano. Después, el juego de luz esparcido por el resplandor de la luna ofrece el volumen, la dimensión de un objeto que se convierte en una pieza artística.

Al detener la mirada en la lectura de los párrafos citados, el lector participa por vía doble al significado simbólico elaborado por el creador; por un lado, examina la disponibilidad de la cicatriz de Copeland como la experiencia del propio cuerpo vivido, y por otro, presencia la imagen del dolor causado por éste en el Otro.

Como lectora, atestiguo un espacio visible de confrontación en la crisis de roles que se desprenden del sujeto de la enunciación ante el escenario de los dos montajes [o del discurso 
puesto en escena]. Ambos ocupan posiciones estratégicas, producen el efecto paradójico del dolor entre aquel que sufre y quien lo produce. Simbólicamente, al mezclar estas acciones y descripciones en la figura del cuerpo como signo, y al proyectar una praxis enunciativa que soporta el peso extratextual de la participación de aquella Historia con mayúscula, en esta historia particular, confirmo la concepción sobre el acontecer que Ramos glosa en su obra, como si la vida de los individuos consistiese en traspasar preludios sucesivos de una edad a otra, de una situación a otra, de la vida como un eterno cruzar umbrales.

Este acto de franquear umbrales historiográficos, en el espacio y en el tiempo, a través de la figura de Mr. Copeland suponen también yuxtaponer estrategias políticas. Podría argüir que el mismo cuerpo del soldado raso es un cuerpo político, porque personaliza significativamente el orden y el poder entre unos y otros. No creo sobre interpretar esta situación al considerar que, si el signo de nación tiene también fronteras, también las posee el cuerpo sentido y sintiente, esa miga de carne abierta a la intemperie del tiempo, ésa que sólo después, en la renovada mirada de un creador de mundos e historias, permite su estetización en la 'perfección del promontorio'.

\section{La conjetura y sus montajes}

El hacer creer es también un artificio de experiencia que muestra diversas habilidades. El procedimiento textual de los montajes o de los encuadres, requieren de algo superpuesto de manera visible, casi fotográfico, a lo conjetural de una trama de matiz policial: ¿Quién asesinó a Mr. Copeland? La enunciación y lo enunciado sintetizan y expanden el recuento y la forma de los hechos atestiguados y conjeturados para poder revelar al autor del homicidio. La conjetura inherente al mencionado "cuento de nunca acabar", mantiene una función retórica y distributiva. La inclusión de sus rimas, con y sin puntos suspensivos, en vez de subtítulos para separar episodios, aluden a las conjeturas en donde el narrador/ personaje Bolaño, adecua sus confabulaciones acerca del homicidio de Mr. Copeland, al tiempo que oculta la artimaña contra Miguel Ángel.

Veamos la distribución del pretexto que posibilita la aventura: "Este era un gato..." (p.35 y p.55), introduce por vez primera a los dos personajes adolescentes, la primera mención es de Miguel Ángel y la posterior del propio Alberto Bolaño, cuando estos gatos contaban con apenas 16 años ("andaban detrás de las gatas"). Páginas adelante, se incluirá el mismo verso en otro episodio cuando Alberto "reconstruye la historia entera" para Miguel Ángel. "Este era un gato con los pies de trapo" (p.81), enuncia y describe las relaciones de los jóvenes con la familia y con la pandilla de Los animales. "Este era un gato con los pies de trapo y los ojos al revés" (p.167), señala el interés de los jóvenes por el sexo y el reconocimiento de Teresa Triana como la misma figura femenina [Tirana], el objeto de deseo de Mr. Copeland. "Este era un gato ¿quieres que te lo cuente otra vez (septiembre de 1973)" (p.180) -con cursivas en el texto- alude a las manifestaciones regionales a favor de ideologías libertarias de izquierda, encabezadas por una maestra de biología, apodada por los jóvenes como, La Mustafá ${ }^{10}$, "la rojilla", y cuya intervención establece el contraste entre la ideología fascista y /o despolitizada de Miguel Ángel y Alberto Bolaño, además de advertir el futuro asesinato de Mr. Copeland. "Este era un gato" (p.238), se repite nuevamente, pero ahora con el objetivo de que Bolaño genere la historia particular y presente del asesinato, sugiriéndole a Miguel, que su padre, Ernesto, es el asesino.

${ }^{10}$ Siguiendo con los apelativos relacionados con el título, Mustafá es un título clásico para nombrar a los gatos. 
“...los pies de trapo" (p.241), es la continuación de la rima, tal como lo sugiere la inserción de los puntos suspensivos al inicio, esta señal metatextual recapitula la específica calumnia, ahora contra Miguel Ángel, sugiriendo a su padre, Ernesto Herrador, que su hijo es el asesino. “...los ojos al revés" (p. 244), vuelve a introducir los puntos suspensivos al inicio, ahora como el tapujo de que quizás Teresa Triana fue la asesina. "quieres que te lo cuente otra vez" (p.247), es la suspensión y la recapitulación de las intrigas realizadas por Bolaño: "Me detuve a esperar los acontecimientos". El protagónico narrador suspende momentáneamente el complot o la propia confabulación, para anudar las conjeturas del asesinato, y para subrayar su asedio ${ }^{11}$. El gatuperio está planeado por este otro gato -Bolaño- que se esfuerza en convertir la figura de Miguel Ángel en el tigre, o en el ángel exterminador que lo identifique con San Miguel Arcángel exterminando al demonio. La última rima, "Quieres que te lo cuente otra vez" (p.301), cierra con un punto final la conspiración del crimen y el discurso de la novela. El lector, si sigue el juego, seguirá inquiriendo, continuará realizando sus propias conjeturas, porque el punto final en una novela es sólo una marca gráfica y no el final de una historia.

Las conjeturas acerca de la H/historia reclaman la existencia del Mr. Copeland, no basta con describirlo de manera física y funcional, por tal razón, para darle realidad histórica a su imagen, el autor mezcla las voces, la del narrador y aquellas que admitan un conocimiento derivado de una serie de contextos verosímiles. Así se incluye rimas escritas en lengua inglesa que confronten la pertinencia de esas otras rimas del "cuento de nunca acabar".

"From the whores of Montezuma ..." (p.62), parafrasea los versos del himno tarareado por los marines, aquí se sugiere como una huella que denuncia el origen y el reencuentro del estadounidense con su tierra natal, el oficio, y aún consigo mismo. La misión de actuar como un francotirador contra el enemigo, al calce del supuesto enamoramiento por la prostituta Teresa Triana [Tirana]. "Kilroy was here" (p.69) sugiere la histórica imagen de un cartoon [obra de Bob Kutzman] que muestra un personaje calvo y muy narigudo que se asoma a un muro y deja su nariz colgando; esta reproducción supone un ícono alegórico que representaba a las tropas aliadas durante la Segunda Guerra Mundial, misma que se pintaba en los muros para que el mundo recordara su participación. En esta novela, la imagen muestra la procedencia ciudadana estadounidense $\mathrm{y}$, sobre todo, vale para satirizar la infundada intervención norteamericana en nuestro país. El narrador describe, en paralelo a la caricatura, la fotografía de aquel muchacho rubio de Oklahoma, que el 21 de abril arribara a Veracruz como uno de tantos marines; páginas después se repite la frase, "Kilroy was here" (p.85), para indicar el segundo desembarco de Mr. Copeland, con las intenciones ya descritas. La misma frase de "Kilroy was here"-21 de marzo de 1974- (p.108), actualiza la maniobra del asesinato, con la fecha de su muerte, el verbo en tiempo pasado pretende dar fe del año de la muerte del soldado norteamericano en el exacto lugar desde donde él le había disparado a tantos mexicanos. Líneas arriba cité la fecha y la rima, "Este era un gato ¿quieres que te lo cuente otra vez" -septiembre de 1973- (p.180), para considerar y confrontar la verosimilitud del asesinato, desde la maquinación hasta su consumación.

Las conjeturas, los montajes, las constantes intervenciones metalingüísticas a cargo de Bolaño subrayan la visibilidad de lo visible de las cosas, cuyo ordenamiento espaciotemporal es

\footnotetext{
${ }^{11}$ Esta forma incisiva de acosar, de cercar, de acorralar al sujeto, identifica a los tantos perseguidores que Ramos configura a lo largo de toda su narrativa, desde Violeta Perú hasta Los motivos de Bayardo. La conjetura también fundamenta mi propia búsqueda como lectora cómplice, no de culto, sino en el convencimiento de que el carácter de la obra descansa en la necesidad de reconvertir la verdad del autor como realidad literaria y viceversa. Porque su forma de verdad sólo puede encontrarse en la literatura, "en el nuevo espacio y el nuevo tiempo con una forma y un orden propios que crea el arte”. [ García Ponce, 2000:159]
} 
semejante a la técnica empleada en las artes visuales. Este paralelismo técnico entre la fícción de lo visible y lo visual, es muy interesante en la narrativa de Ramos. La adecuación del montaje en el relato surge a partir de la mirada que hace visibles a las cosas, a los actores, a los espacios:

Giró la perilla. Abrió. La luz del foco le vaciaba la cara; la limpiaba de sombras, volúmenes, aristas, hasta convertirlo en un dibujo infantil sobre un papel sumamente blanco. 'Se murió, dijo' [...]. Permaneció en el umbral silencioso. [...] El viento había volcado las hojas de un periódico, piezas de ropa por el suelo. En la cama, a la altura de las rodillas, el cuerpo muerto vestido con el short de gringo en vacaciones. La cicatriz en reposo. La camisa abierta dejando a la vista el pecho restirado, las muecas de las costillas, la resequedad de la piel. (p.213)

El reconocimiento ocular en la sintaxis del discurso (porque el punto de visión sobre las palabras es móvil), documenta la composición de un cuadro, la conjunción de marcas tipificadas por el estereotipo del lugar, la situación gestual del hombre muerto, el calco de la vestimenta y la edad de un gringo. La determinación del ángulo de observación restringe, delimita y muestra el hecho de la muerte, al tiempo que mantiene el suspenso, o la conjetura sobre el asesinato. Cuando lo que se aprecia e interpreta no es tanto la puesta en discurso que los impulsa, sino todos los huecos [¿sabremos o no quién ha sido el causante?] que subyacen en el discurso visual, es cuando la imaginación ficcional los cierra y completa. Cuando los huecos de lo real del homicidio, de lo indecible o inconsciente deben lograr su suspensión, es el momento del espectáculo de la mirada que le propone a la ficción la necesidad del montaje, el montaje se impone mediante eso que lo hace real y único, es la cosa [la figura] lo que se convierte en el referente. Ahí, en la pose del cuerpo que encuentra al ojo desde el interior del cuadro como un trampantojo y no como metáfora.

Sobre la verdad del cuerpo vivido, dolorido y fenecido, dan fe y lo atestiguan las distintas tomas fotográficas que describe alguna voz narrativa, esas tomas que pueden considerarse como variantes o actualizaciones de un real más amplio.

Tomas o flashazos, que en su momento deseaba repetir Guerrero, el reportero fotógrafo de La Opinión, siempre en ese vano esfuerzo de una captura original:

Entonces lo vio. Dice que también estaba asomado a la ventana, con las manos apoyadas en el borde, mirando hacia donde él veía. Ahora aún no sabe por qué no le tomó una foto; pero el gesto, la textura de la piel, el perfil de esa cara contra la madera podrida de la ventana, le pusieron en la cámara el primer premio de la Bienal más próxima [...] Entonces pudo verlo de frente, y si antes lo había impresionado su gesto de vigilancia, ahora lo hicieron sus ojos poderosos ('Cómo decirles, jóvenes...Los ojos de un niño en una cara de viejo'). Lo inmovilizaron ahí, a cinco pisos de altura, en una pose de cirquero, sin saber qué hacer... (p.72)

Cuando la mirada de aquel se enfrenta a la mirada de éste, semeja esa doble mirada en donde los actores dirigen la vista directamente al lente de la cámara o, mejor aún, al operador de cámara -aquí del narrador- en donde se verifica la situación de copresencia en un contexto profotográfico atestiguado y no sólo posible. Aquí, la confirmación de la copresencia es más veraz cuando el operador es el fotógrafo, que comenta con los jóvenes, cómo es que sucede una interpelación activa de la situación que ellos no presenciaron, pero que el comentario del 
fotógrafo convierte en la garantía de la realidad de una toma, aunque no de la fotografía; este tipo de acciones resueltas por el autor implícito provoca la visibilidad de un enunciador en un testigo real.

El fundamento estético de estos montajes puede exteriorizarse asimismo en el estadio metalingüístico. A continuación, sólo transcribo un párrafo que muestra tanto la elaboración de los montajes, como la señal metalingüística que lo manifiesta:

...la noticia de la muerte de Mr. Copeland. Me había encargado de dejarlos a todos (a Miguel Angel, a don Ernesto, a Tirana) en la antesala del acontecimiento, a punto del paso final. En cualquiera de los siete días que restaban para que se cumplieran los 60 años exactos de la invasión, alguno de los tres acudiría al cuarto [...] Conforme fue transcurriendo esa semana, la inquietud del principio cedió ante la certidumbre de que, quien tuviera que ser el asesino, dejaría para el último día la escena terminal impelido por su irrefrenable sentido de la estética. (p.252)

En el recuento de lo enunciado existe una voz autoral implicada. Ésta pretende tanto una justicia poética [estética], como un sesgo deontológico que revela el pensamiento del autor empírico cuyo interés en la Historia he comentado. Ramos nos confirma que para escribir una historia/ficción, para rememorar el tiempo que los otros vivieron antes, hay que saber mirar y escuchar, investigar esa otra tradición oral y gráfica de una genealogía que le pertenece a los otros y que, quizás, interese más que la propia. Esta memoria, finalmente convierte a nuestro autor en un acto perfecto de anamnesis.

\section{La marca metalingüística}

Ya he citado y comentado la importancia del metalenguaje en la novela, no obstante, aquí refuerzo la idea consabida de lo literario como este fenómeno que participa tanto de la imaginación, como de un concierto polifónico. La polifonía [o el acto de citar a otro en palabras propias] hace de la narrativa literaria lo que es. Todo fenómeno literario tiene que ver con el conjunto de normas sobre el que está construido, es decir, el conjunto de elecciones que el creador adopta y establece extratextual e intratextualmente. "El lector percibe al autor implícito en la medida que es capaz de desdoblarse, y adoptar el papel de lector del autor y narratario del narrador; a este desdoblamiento (por otra parte, constitutivo del hecho literario) se lo ha llamado lectura irónica o autorreflexiva" (Reyes, 1984, p.105). En los párrafos siguientes, espero coincidir con el lector o lectora de este ensayo, acerca de la disensión entre narrador y autor, originados, precisamente, por esos reenvíos o advertencias en donde la inserción metalingüística demanda y prolonga el juego polifónico de la conjetura:

Todo esto lo reconstruyo al margen del relato de Mr. Copeland; aun así, utilizo sus frases, sus imágenes, las sensaciones que fui rescatando de su deshilvanado monólogo. Supongo que durante su segundo desembarco lo apabulló la culpa del regreso y la inocencia de la primera vez. Se dio cuenta de que su historia no comenzaba, como supuso al principio, ese 21 de abril de 1914, sino muchos años atrás y que, por lo tanto, significaba una simpleza pretender que finiquitara con su muerte. (p.32) 
Las expresiones: reconstrucción, supongo, por lo tanto, significaba, en primera y tercera personas, sugieren el saber historiográfico, emocional y ético, que trama el narrador sobre la vida de Mr. Copeland, en contra de lo que el mismo norteamericano pensara o imaginara.

Las rupturas espaciotemporales del relato, provocadas por los flashbacks y forwards, o las escenas entre el pasado y el futuro en el relato del presente, y aun la sentencia de muerte, son ejemplos enunciativos de esa serie de advertencias que el lector capta, a partir de una voz narrativa, que anuncia el metanarrador ["Todo esto lo reconstruyo al margen del relato"] La muerte inminente, o el preludio de la misma, y que el destinatario ignora, aunado a la observación irónica, encapsula el punto de vista rector de un autor liminar. Las asunciones del narrador se multiplican en el texto, incluso, he advertido, se señalan entre paréntesis:

Después se acostumbró a esperarla en su cuarto ( $\mathrm{Y}$ es esto lo que Mr. Copeland convirtió en ritual [...] resulta obvio que Miguel Angel está dispuesto a desbalancear mis conjeturas con su sonrisa mordaz: pero no encuentro otro asidero. Inferir que Mr. Copeland descubrió en su vacación la posibilidad del reencuentro, de que se alojó en este hotel como medida propiciatoria, y que aguardó los tres meses de su estancia por el regreso de Tirana, explica una conducta que no me atrevo a calificar ni de senil ni de paralógica, pese a que acepto por principio las debilidades de mi hipótesis: con todo, ésta ilumina los actos de Mr. Copeland como partes de un proyecto que estoy en vías de desentrañar). (p.95-96)

Esta serie de hipótesis, conjeturas e inferencias, sumadas a la advertencia de un proyecto, demuestran que detrás del relato del narrador, está la voz del creador; nosotros, los lectores, leemos en consecuencia un segundo relato. Esta mirada autoral, articulada como un discurso hecho de aserciones explícitas, hipotéticas e inferibles, ha sido explicada por Bajtin, en The discourse in the Novel [escrito originalmente alrededor del año 1935]:

Behind the narrator's story we read a second story, the author's story; he is the one who tells us how the narrator tells stories, and also tells about the narrator himself. We acutely sense two levels al each moment in the story; one, the level of the narrator, a belief system filled with objects, meanings and emotional expressions, and the other, the level of the author, who speaks (albeit in a refracted way) by means of his story and through this story [...] If one fails to sense this second level, the intentions and accents of the author himself, then one has failed to understand the work. (en Reyes, 1984, p.106)

\section{Conclusión}

En los párrafos citados de la novela, a partir de la explicación de Bajtin, citada por Reyes, el discurso del autor funciona como ese texto que subyace y emerge, y que será interpretado por el lector según su repertorio. Puedo resumir esta acción en los términos siguientes, Ramos crea a Bolaño e inventa una versión que incluso se superpone al discurso de Bolaño, personaje y narrador. Al mismo tiempo, preexiste su discurso y el discurso del Otro. Esta acción polifónica es la que todos los lectores aceptamos como el rasgo irónico de la ficción, repito, o el atractivo juego de la suspensión de la incredulidad, hay que creer que las narraciones, descripciones e imágenes no son deliberadas, aunque lo sean. Sólo me queda reiterar que interpreto la concepción 
del mundo ficticio de Luis Arturo Ramos como una muestra del mundo abierto (H/histórico, político, cultural, poético) a partir de las conjeturas que él mismo realiza, su novela no intenta ofrecernos respuestas, por el contrario, propone preguntas, dudas, que nosotros, los lectores, no habíamos formulado. Si bien es cierto que su escritura penetra con fuerza ética o moral, también es verdad que su narrativa, muestra el oficio creativo de un fabulador. Lo imaginario en Ramos se convierte en un acto de enunciación en donde el yo del lector in situ no iguala la identidad y el contexto compositivo de la obra. Hay que leerlo, en consecuencia, como el autor de una obra irrepetible, una obra que nos facilita advertir el sentir estético de la ficción en nuestro presente extra novelesco. El sentir y el mirar de los objetos (personajes, espacios, tiempos) coinciden fenoménicamente con la deliberación poética e historiográfica que nos une, en tanto autor y en cuanto a esta lectora cómplice que pretende acercase al texto con una adecuada y cercana conciencia crítica.

\section{Bibliografía}

Barthes, R. (1989). La cámara lúcida-Nota sobre la fotografía-. Barcelona: Paidós.

Campos y Moreno. (Comps.) (2005). Acercamientos a la narrativa de Luis Arturo Ramos. Cd. Juárez: Universidad Autónoma de Ciudad Juárez.

Dorra, R. (2011). La casa y el caracol. México/Puebla: Plaza y Valdes/Benemérita Universidad Autónoma de Puebla.

Eco, U. (1997). Interpretación y sobreinterpretación. España: Cambridge University Press Sucursal España-.

Filinich, M. I. (2003). Descripción-Enciclopedia semiológica- Buenos Aires: EUDEBA.

García Ponce, J. (2000). Tres voces. México: Aldus.

Greimas y Fontanille. (1995). Semiótica de las pasiones. México: Siglo XXI.

Landowski, Dorra y De Oliveira. (1999). Semiosis, estesis, estética. São Paulo/Puebla, EDUC/UAP.

Ramos, L. A. (1987). Éste era un gato. México: Grijalbo.

Vázquez Rentería, V. (2012). "De la escritura como inmersión en la opacidad pegajosa de la condición humana: Éste era un gato" en Teresa García Díaz, (coord.) La poética de la percepción y los intersticios de la memoria: Luis Arturo Ramos. Xalapa: Universidad Veracruzana. 